\title{
Capacity of the Working Memory and Its Relationship with the Ability to Retain Information among Secondary Stage Students in Amman
}

\author{
Abdelraouf Al-Yamani ${ }^{1}$, Nadia Hayel Al-Srour ${ }^{2}$, Safa AlAli ${ }^{3}$ \\ ${ }^{1}$ Al-Isra’a University, Amman, Jordan \\ ${ }^{2}$ The University of Jordan, Amman, Jordan \\ ${ }^{3}$ The Hashemite University, Zarqa, Jordan \\ Email: dr-abdelraouf-alyamani@hotmail.com, special_education10@yahoo.com
}

Received September $19^{\text {th }}$, 2013; revised October $19^{\text {th }}$, 2013; accepted October $26^{\text {th }}$, 2013

\begin{abstract}
Copyright (C) 2013 Abdelraouf Al-Yamani et al. This is an open access article distributed under the Creative Commons Attribution License, which permits unrestricted use, distribution, and reproduction in any medium, provided the original work is properly cited.
\end{abstract}

\begin{abstract}
The purpose of this study is to explore the capacity of the working memory among secondary stage students in Amman second educational directorate and its relationship with their ability to retain information. To explore their level of working memory, listening test period developed by (Daneman \& Carpenter, 1980) was used, and the test consisted of 40 items. Moreover, the researcher used retention ability test in biology with 20 items. The sample of the study was selected from eight schools through random clustering total 293 male and female students in the school year 2010/2011. The findings of the study showed that the capacity of the working memory among students was high and their ability to retain was low. There is a positive significant relationship between the capacity of the working memory and the level of the ability to retain information. Based on the findings of the study, the researchers recommended the need of taking careful attention to mnemonics and the strategies that may help working memory in restoring and processing, concentrating in teaching methods that help students to employ more than one sense in addition to the direct experience in teaching to increase the working memory capacity among students and help them to improve information processing strategies. Moreover, they conduct more studies on working memory and its relationship with psychological and cognitive variables in other educational stages.
\end{abstract}

Keywords: Capacity of Working Memory; Ability to Retain; Secondary Stage Students; Amman Second Educational Directorate

\section{Introduction}

Memory played a big role in human's life and in his social, cognitive and psychological activity. The memory not only keeps the cognitive storage for humans, but also through this storage forms the normal personality and helps the individual to imagine, judge, visualize, induce and practice all intellectual activities.

\section{Memory}

Scientists tried to study the human memory as well as memorization, storage and recall; they found that there are three types of memory: Sensory memory, short-term memory, and longterm memory (Leahey, 2003). The information are selected by the sensory memory to reach its final destination to the long term memory and processed in the short term memory which is called later (the working memory) that represents the individual recognition to the process of retaining information for a short period of time until he makes a decision to process it and sending it to the long term memory (Al-Sahreef, Mustafa, \& Mahmoud, 2005).

Baddeley (2005) mentioned that there is a need to shift from short term memory to the working memory as it is not storage or a route for data but it contains processing information to send it to the long term memory. Jarrold \& Towse (2006) indicated that the process of employing information and integrating it to achieve a certain cognition goal distinguishing the working memory from the short term memory.

Dehn (2008) mentioned that the working memory is different from the short term memory in many aspects, those contributed in changing the concept as follows:

- The short term memory is restricted in two domains (verbal and visual) while the working memory is more general.

- The short term memory keep information whiles the working memory process and keeps information.

- The short term memory activates the stored information in the long term memory while, the working memory guides the recall of the needed information from the long term memory.

- Short term memory is limited to the administrative functions while, the working memory conducts executive functions.

\section{Working Memory}

The working memory is one of the most important concepts 
in the cognitive psychology science since it provides is with application for the cognitive function in general and for the academic teach in particular (Davis, 2011). Jonidei \& Nee (2006) argued that the working memory is an important cognitive ability contributing in the higher cognitive functions as it enters in some higher skills such as reading comprehension, logical training and problem solving.

Baddeley (1986) indicated that working memory is a comprehensive system works to unify the functions and subsystems by the long-term memory, and short-term memory. Duff \& Logie (2001) defined the working memory as the ability to process information and temporary storage for a short time. Moreover, Lepine, Barrouillet \& Camos (2005) considered it a cognitive central process for the effective processing of information.

Dehn (2008) argued that the working memory is Brain's ability to retain information for a short period of time, and employ them in different cognitive tasks, he pointed out that the three working memory and executive functions are as follows:

1) Executive memory: Conduct selective attention, ability to focus on relevant information with the work at the same time to control the sources of distracting, while coordinating between different cognitive activities.

2) Auditory memory: the part associated audio information, which works on information processing, storing or demise of memory, and verbal information stored two seconds or less.

3) Visual memory: the responsible uncle processing information presented visually.

The capacity of the working memory among individuals can be measures through some knowledge or sentences or verbal tasks or even visual ones in order to start simple memorization based on recalling and restoring as well as complex memorization based on retention, processing and recalling (Gathercole \& Alloway, 2009).

One of the first models that have been developed to measure the capacity of the working memory Baddeley model in 1974, which he redeveloped in 2000, has the executive process, which controls the operations of attention, information processing, in addition to the three systems within the memory: the phonological repetition, storing visual and spatial information and the main memory (Baddeley, 2000).

Afterwards, many models were developed to measure the capacity of the working memory among individuals, one of them is Daneman \& Carpenter (1980) model containing a set of sentences read by the individual, and then he must remember them in the same order in which they presented to him. In addition, there is Turner \& Engle (1989) scale which is based on mathematical tasks more than sentences.

When testing the capacity of the working memory its capacity limitation must be considered as it fails to help people to recall information especially if there are distracting sources or doing complex tasks during information retention (Gathercole \& Alloway, 2009). Abu Al-Naser (2009) mentioned that the time limit for keeping information in the working memory ranged from $(20$ - 30) seconds most of the time.

Individuals differ in the capacity of working memory and the difference attributed to several factors such as: cognitive development, where increasing the capacity of working memory from childhood to adolescence to adulthood, and an individual's ability to process information, and differences in the capacity of working memory among individuals (Davis, 2011). Al-Zayyat (1998) pointed to a set of factors that affect the working memory capacity and its effectiveness including: time speech or presentation, anxiety or frustration, coding style and quality, meaning, and emotional and psychological factors of the individual.

Since information in the working memory can be lost it must be activated for retention purposes.

In order to keep the information in working memory for 30 seconds and not more than a few minutes, and access to longterm memory, the individual uses many strategies and methods to enable him from retention (Abo Alam, 1996; Abu Nasr, 2009). Al-Dardeer and Abdullah (2005) mentioned to some of these methods, including the degree of concentration, and the type of recitations, and learning strategies, and the inevitable impact of previous learning.

Retention can't be noted directly but it can be seen through repetition and recognizing as well as information retrieving (Al-Melhem, 2003). Keeping or retention means the ability to retain what is taught. Al-Dafaee and Al-Muneffe (2006) argued that this concept refers to the core of the subject or its main elements.

Therefore, it is evident that the working memory has its importance in school learning and in retaining information the restoring it and retrieving it when needed. The process of retaining information doesn't appear directly but through memorizing and recalling process and this can't be done except through the models of testing the working memory capacity mentioned in educational psychology studies. The researchers in this study sought to test the capacity of the working memory and its relationship with retention among secondary stage students in Amman governorate.

After reviewing the related literature and previous studies it was evident that there is a scarce- according to researchers- in the studies addressing this issue directly. One study aimed to measure the role of working memory capacity and gender in reading comprehension in a sample of 230 male and female students in the secondary stage in Irbid city was conducted by Al-Hamori and Khsawneh (2011) they used listening period test to measure the working memory capacity and reading comprehension. The study concluded that there are significant statistical differences between the averages of students' performance on the test capacity of working memory, and test reading comprehension due to gender, in favor of females. Findings revealed that reading comprehension is affected by the capacity of working memory, and there was no effect of the interaction between the capacity of working memory and gender in reading comprehension.

Moreover, Swanson (2011) studied the role of working memory in children's growth in mathematical problem solving was examined in a longitudinal study of children $(\mathrm{N}=127)$. A battery of tests was administered that assessed problem solving, achievement, working memory, and cognitive processing (inhibition, speed, phonological coding) in Grade 1 children, with follow-up testing in Grades 2 and 3. The results showed that Grade 1 predictors that contributed unique variance to Grade 3 word problem-solving performance were working memory, naming speed, and inhibition and (b) growth in the executive component of working memory was significantly related to growth in word problem-solving accuracy. The results support the notion that growth in the executive system of working memory is an important predictor of growth in children's problem solving beyond the contribution of cognitive measures of inattention, inhibition, and processing speed as well as achieve- 
ment measures related to calculation and reading.

In a predictive study to investigate the ability of working memory in predicting the ability to solve problems among students, Zheng, Swanson, \& Marccoulides, 2011) selected a random sample of children in Grades 2, 3, and $4(\mathrm{~N}=310)$. A battery of tests was administered to assess problem-solving accuracy, problem-solving processes, working memory, reading, and math calculation. Structural equation modeling analyses indicated that all three working memory components significantly predicted problem-solving accuracy, reading skills and calculation proficiency mediated the predictive effects of the central executive system and the phonological loop on solution accuracy, and academic mediators.

Another study dealt with Retention was conducted by Abdelhaq \& Al-Khatib (2011) the purpose of the study was to explore the maintain the levels of seventh grade in patterns of linguistic and grammatical concepts that they previously studied after the implementation of educational development based on the knowledge of economy in Jordan. The research has been limited on a sample randomly selected from Zarqa schools, consisting of 490 students. The test has been designed according to the table specification, taking into account the difficulty index and discrimination and procedures for them validity and reliability of the test were conduct. The research revealed that $24 \%$ of the sample of retention was satisfactory set by the arbitrators $68 \%$. Moreover, there is no statistically significant difference between result of male and female.

In the context of the relationship between maintaining and the strategies of memory activation Barakat (2010) studied the strategies that are used by the Al-Quds Open University Students to enhance the maintenance of information so that enable them easily remembering it later. To achieve this purpose, the researcher randomly selected a stratified sample consisted at 232 students (100 male, and 132 female), from Al-Quds Open University in Tulkarem; whom respond to a 25-item instrument which was designed for the purpose of this study. The results revealed that the students focus in using the strategies in medial level, the results also showed that the most five effective strategies in enhancing maintaining and remembering information in arrangement were: Underline the important parts in the text, put marks and signs on the important parts, using the distributed study, understanding instead of memorizing, and joining parts of the material with each other. The results indicated that there were no significant differences in using these strategies among students due to gender, specialization, and academic achievement variables.

In order to explore the correlation relationship between the capacity of the working memory and reading comprehension Jincho, Namiki \& Mazukam (2008) studied the effects of verbal working memory and cumulative linguistic knowledge on reading comprehension among 62 male and female students in Useda University in Japapn within two tests the Japanese Reading Span Test cumulative linguistic knowledge was assessed using information, vocabulary, and similarity subtests of the Wechsler Adult Intelligence. The results showed that verbal working memory and cumulative linguistic knowledge were independent of each other, and that verbal working memory and cumulative linguistic knowledge independently contributed to reading comprehension.

In the other hand, Al-Luqta (2007) studied the relationship between the capacity of the working memory, cognitive pattern and the speed of cognition in mental operations used to solve problems among Jordanian students. The researcher selected a random cluster sample totaling 318 students in the first secondary scientific stage in Amman area. The researcher administrated working memory capacity test, solving problems test, cognitive pattern test and cognition speed test. The findings related to the memory capacity showed that there is positive correlation relationship between the capacity of the working memory, cognitive pattern, cognition speed and problem solving.

Al-Khatib (2005) study aimed at finding out the retention of grade eight students of the grammatical and inflectional concepts required for grades five and six. The sample of the study consisted of 467 students. To answer the questions of the study, the researcher devised a special achievement test. The appropriate statistical treatment was used. The results showed that students' retention of the grammatical and inflectional concepts was $63.6 \%$ below the acceptable level agreed upon by the team of juries which was $70 \%$. The results also showed that there were significant differences in the retention of these concepts between female and male students in favor of females.

In another study named working memory as short term memory Maleha (2003) studied the relationship between short term memory and long term memory and the ability to solve problems among tenth graders. The sample of the study consisted of 92 male and female students. To achieve the aim of this study the researcher used three tests, short term memory test consisted of 20 Arabic and foreign words, the long term memory test consisted of a story with ten Arabic unfamiliar names and the mathematical problem solving test. The findings of the study indicated that there were no significant statistical differences between the means of students' scores in the ability to solve problems test and their scores in the short memory test. There is a relationship between male and female students' scores in the ability to solve problems and the interaction between then scores in both tests of memory.

In an empirical study MacNamara \& Scott (2001) examined the role of strategy use in working memory tasks by providing short-term memory task strategy training to participants. In Experiment 1, the participants received four sessions of training to use a story-formation (i.e., chaining) strategy. There were substantial improvements from pretest to posttest (after training) in terms of both short-term memory task and working memory task performance. Experiment 2 demonstrated that working memory task improvement did not occur for control participants, who were given the same amount of practice but were not provided with strategy instructions. An assessment of participants' strategy use on the short-term memory task before training indicated that more strategic participants displayed better working memory task performance and better verbal skills. These results support our hypothesis that strategy use influences performance on working memory tasks.

Meanwhile, Goolkazian \& Foos (2002) studied the separate cognitive demands of processing and storage in working memory and looked at how effective the coordination was when items for storage varied in format/modality. A sentence verification task involving arithmetic facts was combined with a span task involving two to six items presented in picture, printed word, or spoken word format. The first two experiments were the same, except for the added requirement of articulation of the math sentence in Experiment 2. Experiment 3 varied the length of the span item and compared recall with recognition performance. The results showed that both spoken words and 
pictures produced superior recall and recognition, as compared with printed words, and are consistent with Baddeley and Logie's (1999) and Mayer's (2001) models of working memory. Also, the differences in processing performance across spans varied with the difficulty of the task but showed the strongest support for the resource allocation model.

It is noted that some of the studies dealt with issue of working memory with other variables such as retention and the same with other retention studies. Therefore, the current study is different from those studies as it aimed to explore the relationship between the capacity of the working memory and retention among secondary stage students in Jordanian environment in order to add a new knowledge in this field.

\section{Study Objectives and Questions}

The purpose of this study is to explore the capacity of the working memory and its relationship with the ability to retain among secondary stage students in Amman governorate in Jordan. In addition, the study aimed to explore if there is statistical differences in the working memory capacity and retention attributed to gender and achievement. Specifically, the study sought to answer the following questions:

1) What is the capacity of working Memory among secondary stage students in Amman governorate?

2) What is the level of conserving information among secondary stage students in Amman governorate?

3) Is there a significant correlation relationship at the level of $(\alpha=0.05)$ between the capacity of working memory and the level of conserving among secondary stage students in Amman governorate?

\section{Study Significance}

The importance of this study is based on the importance of human memory and its role in learning and teaching as well as social interaction, especially the working memory which is considered as the center of processing information to move it to the long term memory which is the base of the social, emotional and cognitive structure of individuals.

Knowing the types of memory and the relationship between the work memory and retention may help students in planning to use methods and strategies to enhance the levels of working memory capacity as well as fostering the ability to retain and processing information. The importance of the current study can be summarized as follows:

- Theoretical aspect: The new addition to the knowledge and to the Arabic library in order to help students to understand the relationship between the working memory capacity and retention of information.

- Practical aspect: The consequences of the study findings which can be transferred to the educational field. Moreover, the findings can be a good assistant to teachers in the field and even for students to enhance their ability to process information and restore them in the long term memory.

- Objective aspect: The novelty of the subject since there are no studies in the same field.

\section{Procedural Definitions}

The researchers present the terms related to the study despite the fact that there is no agreement on the meaning of those terms. However, the definitions are meant for more explana- tion:

- Working Memory: The ability of the brain to retain information for a short period of time and employing it in different cognitive tasks (Dehn, 2008: p. 23). For the purposes of this study it is the scores of the sample through their answers on the listening period test developed by (Daneman \& Carpenter, 1980) and used in Al-hamouri and Khsawneh (2011).

- Ability to retain: It is the ability to conserve what had been learned (Abu Alam, 1996: p. 348). Al-Dafee and Al-Muneffe (2006: p. 136) argued that this concept is about conserving the core of the subject or its main elements. For the purposes of this study it is it is the scores of the sample through their answers on the retention test.

- Secondary Stage students: Secondary stage students in the Academic streams: scientific, IT and literature in Amman II educational directorate in the schooling year 2010/2011.

\section{Limitations of the Study}

Generalizing the findings of this study is limited to:

1) Objective limitations: The study investigates the correlation relationship between the capacity of the working memory and its relationship between the ability to retain information among secondary stage students in Amman Governorate.

2) Human Limitations: The study is limited to the Secondary stage students in the Academic streams: scientific, IT and literature.

3) Place and time limitations: The study was conducted in Amman city in the schooling year 2010/2011.

4) The limits of this study are as follows:

- The psychometric properties of the tools of this study.

- The validity and objectivity of the samples' answers on the tests which are applied.

\section{Methodology \& Procedures}

\section{Study Methodology}

The researcher adopted Survey approach which is considered one type of descriptive studies that describe the characteristics of students as it is as well as studying the correlation relationship between the variables (Al-Hamdani, Al-Jadri, Qandlji, \& Abu-Zina, 2006). The researcher adopted this approach since it is appropriate for the nature of this study and its questions; this approach provides an accurate description of the phenomena through collecting data and research design. Moreover, it helps in organizing data and findings the correlation relationship between the main variables, statistical differences of personal information in order to reach accurate information.

\section{Study Population}

The population of the study consisted of secondary stage students in Academic streams: scientific, information technology and Literature in Amman second Educational Directorate in the schooling year 2010/2011 totaling (5327) male and female students (2547 males, 2780 females) according to the manual of the planning and Educational Research directorate in the ministry of education in 2010/2011.

\section{Study Sample}

The researcher selected 293 male and female students as a 
partial sample drawn from the population with the same characteristics. The sample was selected through random cluster sampling by using (Bartlett, Kotrlik, \& Higgins, 2001) model as the researcher selected four classes from males schools and four classes from female schools randomly. Therefore, the sample consisted of 174 male students and 119 female students. Table 1 shows the distribution of the sample.

\section{Study Instruments}

In order to investigate the capacity of the working memory and its relationship of maintain information among secondary stage students the researcher administrated two tools:

\section{Listening Period Test}

The researcher administrated (Daneman \& Carpenter, 1980) used in Al-Hamour and Khsawneh (2011). The test consisted of two parts, each part contained five gradual levels of difficulty from the second level which includes two sentences to the sixth level includes six sentences, the total number of sentences is 40, 20 in each part. Knowing that the sentences are simple and the test required recalling the last word of the sentence after hearing it.

To ensure that the student heard all the sentences, they were divided into 20 correct sentences and 20 wring sentences, the student's marks wrong or correct in front of the sentence.

To check validity the scale was rated by 10 specialized raters in Educational psychology and measurement at Jordanian universities within its correctness and appropriateness. The researcher considered all comments in the final draft of the test.

In order to calculate validity the researcher used Cronbach Alfa Confinement through administrating the tools on 25 students, the reliability ratio totaled 0.85 .

\section{Retention Ability Test}

The researcher developed an achievement test to measure first secondary class students ability to conserve Biology in the first semester of the schooling year 2012/2013. After reviewing the book and designing detail schedule the test was developed accordingly with consideration to Bloom taxonomy. The test was multiple choice form in order to be easy in application and correction. The test consisted of 25 items with four alternatives in its draft form.

1) Validity of the Test

To check validity the scale was rated by 10 specialized raters in Educational psychology and measurement at Jordanian universities within its correctness and appropriateness. The researcher considered all comments in the final draft of the test within an agreement rate of $80 \%$ between raters. The comments contained omitting five items and modifying other items, then evaluation level was omitted and the description schedule was as show in Table 2.

2) Reliability of Retention Ability Test

A pilot sample totaling 23 students was selected from one of the first secondary classes in Amman II educational directorate from outside the sample. The researcher administrated the test two times within a period of two weeks. After correcting and scoring the test Pearson coefficient was used showing 0.86 validity rate. This means that the test is reliable for the purposes of the study. Moreover, internal constancy by using Cronbach Alfa was used totaling 0.89 showing that the test can be administrated on the study sample.
3) Difficulty and Discrimination Coefficients

Coefficients have been calculated for difficulty and discrimination for each item of the test, through experimentation initial exploratory test on the sample, the number of students 23 students. After, correcting students' responses coefficients of difficulty and discrimination factors for each item of the test were calculated, the coefficients ranged from discrimination test between $0.25-0.72$ and difficulty ranged between 0.31 0.77 , Table 3 presents the values.

4) Scoring the Retention Test Ability

The achievement test consisted of 20 multiple choice items; one mark was given for the correct answer while zero was given for the wrong answer. Therefore, the total score for the test was 20.

\section{Study Variables}

The study consisted of two main variables, those are:

- Working Memory.

- Retention Ability.

\section{Study Procedures}

In order to achieve the aim of this study the researcher carried out the following procedures:

- Reviewing the related literature and previous studies in order to develop the tools of this study.

- Determining the study population in Amman Educational Directorate by using cluster sampling to draw the sample.

- The researcher administrated the tools manually by visiting schools and explaining the aim of the study and its procedures then supervising the process of collecting data from students.

- Extracting data and processing them on (SPSS) software.

- Interpreting results through its logical reasons according the related literature and previous studies then presenting recommendations.

\section{Statistical Analysis}

The researcher used the related statistics to answer the study questions as follows:

- For the first and third question the researcher used means and standard deviations.

- To answer the third question the researcher used Pearson Coefficient.

\section{Findings and Discussion}

Hereby the findings of the study with detailed discussion for each result.

\section{The First Question: What Is the Capacity of Working Memory among Secondary Stage Students in Amman Governorate?}

To answer this question the means and standard deviations were calculated for the capacity of working memory among secondary stage students in Amman governorate. The findings showed that the mean of the working memory capacity totaled 29.50 with a standard deviation of 6.13 showing a high degree, this indicates the ability of students to process information and using it in addition to the ability to use their knowledge and 
Table 1.

Frequencies and percentages according to the variables.

\begin{tabular}{|c|c|c|c|}
\hline Variable & Categories & Frequency & $\%$ \\
\hline \multirow{2}{*}{ Gender } & male & 174 & 59.4 \\
\hline & female & 119 & 40.6 \\
\hline \multirow{4}{*}{ Accumulative average } & Less than 70 & 59 & 20.1 \\
\hline & 70 - less than 80 & 128 & 43.7 \\
\hline & 80 more than & 106 & 36.2 \\
\hline & & 293 & 100 \\
\hline
\end{tabular}

Table 2.

Description schedule.

\begin{tabular}{cccccccccc}
\hline \multirow{2}{*}{ Bloom } & \multicolumn{2}{c}{ Memorization } & \multicolumn{2}{c}{ Understanding } & \multicolumn{2}{c}{ Implementation } & \multicolumn{2}{c}{ Total } \\
\cline { 2 - 10 } Taxonomy Unit & Freq & $\mathbf{\%}$ & Freq & $\mathbf{\%}$ & Freq & $\mathbf{\%}$ & Freq & \% \\
\hline Unit One & 4 & $20 \%$ & 3 & $15 \%$ & 4 & $20 \%$ & 11 & $55 \%$ \\
Unit two & 3 & $15 \%$ & 4 & $20 \%$ & 2 & $10 \%$ & 9 & $45 \%$ & $100 \%$ \\
Total number of questions & 7 & $35 \%$ & 7 & $35 \%$ & 6 & $30 \%$ & 20 & $100 \%$ \\
\hline
\end{tabular}

Table 3.

Difficulty and discrimination coefficients of retention ability test.

\begin{tabular}{cccccc}
\hline Item & Difficulty & Discrimination & Item & Difficulty & Discrimination \\
\hline 1 & 0.68 & 0.31 & 11 & 0.31 & 0.56 \\
2 & 0.3 & 0.33 & 12 & 0.52 & 0.36 \\
3 & 0.3 & 0.34 & 13 & 0.34 & 0.62 \\
4 & 0.33 & 0.42 & 14 & 0.41 & 0.68 \\
5 & 0.72 & 0.39 & 15 & 0.41 & 0.77 \\
6 & 0.52 & 0.46 & 16 & 0.55 & 0.58 \\
7 & 0.62 & 0.41 & 0.7 & 0.33 \\
8 & 0.34 & 0.35 & 17 & 0.66 & 0.51 \\
9 & 0.55 & 0.75 & 19 & 0.38 & 0.7 \\
10 & 0.38 & 0.35 & 20 & 0.48 & 0.31 \\
\hline
\end{tabular}

memorization aids to store the information in the working memory. The researcher noted that students used coding, repetition and conceptual images as those can help in increasing working memory in order to conserve information (Gathercole \& Alloway, 2009). Since the working memory capacity doesn't exceed one minute (Abu Al-Naser, 2009) this agreed with the method of testing students, as researchers noted that capacity working memory of the students are as a model in tests with little number of questions. The memory decreased when the test item increased, this led to high scores in this test.

Individuals differ in the working memory capacity due to several factors such as knowledge growth as the ability of the working memory increase from childhood to adolescence and adultness (Davis, 2011). Al-Zayyat (1998) indicated that there are many factors affecting the working memory such as: display time, anxiety, frustration, type of coding and the psychological factors of the individuals.

Moreover, since the information in the working memory can be lost therefore, it must be activated in order to maintain information and to keep those information for 30 seconds or several minutes then it goes to the long term memory. To keep information the individual uses many strategies and mnemonics (Abu Alam, 1996; Abu Al-Naser, 2009). Aldardeer \& Abdullah
(2005) mentioned some of those strategies such as concentration degree, memorization type, learning strategies and the absolute effect of pre-learning.

With regard to the comparison with previous studies there were no studies discussed this issue-according to the researchers - so, there is no comparison within agreement or disagreement.

\section{The Second Questions: What Is the Level of Conserving Information among Secondary Stage Students in Amman Governorate?}

To answer this question the researcher calculated means and standard deviations for the level of conserving information among secondary stage students in Amman governorate. The findings showed that the means of students ability totaled 13.86 with a standard deviation of 3.61, this shows a low level and this might be referred to the test which measures keeping information from previous semester and this long period may cause forgetting those information as the capacity of the working memory alone is not enough to keep information for a long period of time and moving it to the long term memory, and there are other important factors such as the strategies used by 
students or the teaching methods which led to this low score.

The findings of this question are consistent with the findings of Al-Khatib (2005) study which showed that student are weak in conserving the mentioned concepts as the rate was 63.6 shoeing a low degree of Retention. However, the findings disagreed with Abdelhaq \& Al-Khatib (2011) study which showed that $24 \%$ of students conserve information in an acceptable manner.

\section{The Third Question: Is There a Significant Correlation Relationship at the Level of $(\alpha=0.05)$ between the Capacity of Working Memory and the Level of Conserving among Secondary Stage Students in Amman Governorate?}

To answer this question Pearson Coefficient was calculated between the capacity of working memory and the level of conserving among secondary stage students in Amman governorate. Table 3 presents the findings.

Table 4 shows that there is a positive correlation relationship between the capacity of the working memory and the level of conserving information among secondary stage students in Amman governorate. This indicates that a student who has high memory capacity has the ability to retain for a long time if he uses of working memory strategies as well as processing information strategies. The working memory is not a storage or a route for data but it contains processing and making information ready to be moved to the long term memory. (Jonidei \& Nee, 2006) mentioned that the working memory is an important cognitive ability contributing in the higher cognitive functions such as reading comprehension, logical training and problem solving.

Since the information in the working memory can be lost therefore, it must be activated in order to maintain information and to keep those information for 30 seconds or several minutes then it goes to the long term memory. To keep information the individual uses many strategies and mnemonics (Abu Alam, 1996; Abu Al-Naser, 2009). Aldardeer \& Abdullah (2005) mentioned some of those strategies such as concentration degree, memorization type, learning strategies and the absolute effect of pre-learning. With regard to the comparison with previous studies there were no studies discussed this issue-according to the researchers-so, there is no comparison within agreement or disagreement.

\section{Recommendations}

Based on the findings of the study, the researcher recommended the following:

Table 4.

Pearson coefficient was calculated between the capacity of working memory and the level of conserving among secondary stage students in Amman governorate.

\begin{tabular}{ccc}
\hline Variable & Correlation & Retention ability \\
\cline { 2 - 3 } Working memory & $\mathrm{R}$ & $0.651^{* *}$ \\
& Sig. & 0.000 \\
& No. & 293 \\
\hline
\end{tabular}

Note: ${ }^{*}$ Sig. (0.05). ${ }^{* *}$ Sig. (0.01).
- The findings showing the capacity of the working memory to be high in leading to the detecting of students methods used in keeping this memory and benefiting other students.

- The need of taking careful attention to mnemonics and the strategies that may help working memory in restoring and processing.

- Concentrating in teaching methods that help students to employ more than one sense in addition to the direct experience in teaching to increase the working memory capacity among students and help them to improve information processing strategies.

- Developing teaching methods to cope with human memory and concentrating in cognitive methods that increase students' Retention.

- Developing learning skills among students to enable them from increasing their ability to conserve information.

- Conducting more studies on working memory and its relationship with psychological and cognitive variables in other educational stages.

\section{REFERENCES}

Abdelhaq, Z., \& Al-Khatib, M. (2011). Levels of seventh grade maintaining of language types, grammatical concepts after educational base knowledge developments in Jordan. Al-Najah Scholar, 25, 474508.

Abu Alam, R. (1996). Educational psychology. Kuwait: Dar Al-Qalam Publishers.

Al-Dafaee, H., \& Al-Munefe, A. (2006). Educational psychology: Its practical implications. Sana'a: Abarri Studies Center.

Al-Dardeer, A., \& Abdullah, J. (2005). Cognitive psychology science: Readings and modern applications. Cairo: Books World Press.

Al-Hamdani, M., Al-Jadri, A., Qandlji, A., \& Abu-Zina, F. (2006). Methods of scientific research: Basics of scientific research. Amman: Al-Wrraq Press.

Al-Huri, F., Amna, K. (2011). The role of working memory capacity and social gender in reading comprehension. Jordanian Educational Journal, 7, 221-232.

Al-Khatib, M. (2005). The extent of maintaining grammatical concepts by 8 th graders in fifth and sixth grade. Educational \& Psychology Journal, 6, 36-58.

Al-Luqtaa, R. (2007). Working memory capacity and cognitive style (verbal/imaginative) and cognition speed in its relationship with mental processes used to solve problems among Jordanian students. Ph.D. Dissertation, Amman: Amman Arabic University.

Al-Melhm, E. (2003). Activating the child abilities on learning. Damascus: Alaaldin Publishers.

Al-Shareef, S., Mohammad, I., \& Mustafa, A. (2005). Modern trends in measuring intelligence and human memory. Al-Ryadh: Dar ALZahra Publishers.

Al-Zayyat, F. (1998). Biological and psychological basics of mental and cognition activity. Cairo: Book World Press.

Al-Zayyat, M. (2009). Concentration power and memory enhancement. Cairo: Arabic Training Group for Publishing.

Baddeley, A. D. (1986). Working memory. New York: Oxford University Press.

Baddeley, A. D. (2000). The episodic buffer: A new component in working memory? Trends in Cognitive Sciences, 4, 417-423. http://dx.doi.org/10.1016/S1364-6613(00)01538-2

Baddeley, A. D. (2003). Working memory: Looking back and looking forward. Nature Reviews, Neuroscience, 4, 829-839. http://dx.doi.org/10.1038/nrn1201

Barkat, Z. (2010). Memory activation strategies used by Al-Quds Open University students to enhance their ability to maintain information and recalling them. Al-Njah Journal, 24, 2527-2558.

Bartlett, J., Kotrlik, J., \& Higgins, C. (2001). Organizational research: Determining appropriate sample size survey research. Information 
Technology Learning and Performance Journal, 19, 43-51.

Daneman, M., \& Carpenter, P. A. (1980). Individual differences in working memory and reading. Journal of Verbal Learning and Verbal Behavior, 19, 450-466.

http://dx.doi.org/10.1016/S0022-5371(80)90312-6

Davis, D. (2011). Identifying working memory capacity: A study of two working memory assessment tools. Unpublished Master's Thesis, Menomonie, WI: University of Wisconsin-Stout.

Dehn, M. J. (2008). Working memory and academic learning assessment and intervention. New Jersey: John Wiley \& Sons, Inc.

Department of Planning and Educational Research (2011). Ministry of Education. Amman: Jordan.

Duff, S., \& Logie. R. (2001). Processing and storage in working memory span. The Quality Journal of Experimental Psychology, 54A, 3148.

Gathercole, S. E., \& Alloway, T. P. (2009). Working memory and learning: A practical guide for teachers. Los Angeles, CA: Sage.

Goolkazian, P., \& Foos, P. (2002). Presentation format and its effect on working memory. Memory \& Cognition, 30, 1096-1105. http://dx.doi.org/10.3758/BF03194327

Jarrold, C., \& Towse, I. (2006). Individual differences in working memory. Neuroscience, 139, 39-50.

http://dx.doi.org/10.1016/j.neuroscience.2005.07.002

Jincho, N., Namiki, H., \& Mazuka, R. (2008). Effect of verable working memory and cumulative linguistic knowledge on reading comprehension. Japanese Psychological Research, 50, 12-23. http://dx.doi.org/10.1111/j.1468-5884.2007.00358.x
Jonidei, J., \& Nee, E. (2006). Brain Mechanisms of proactive interference in working memory. Neuroscience, 139, 181-193. http://dx.doi.org/10.1016/j.neuroscience.2005.06.042

Leahey, T. (2003). Cognition and learning. Handbook of psychology. Hoboken, NJ: John Wiley and Sons, Inc.

Lepine, R., Barrouillet, P., \& Camos, V. (2005). What makes working memory spans so predictive of high-level cognition. Psychonomic Bulletin and Review, 12, 165-170. http://dx.doi.org/10.3758/BF03196363

MacNamara, D., \& Scott, J. (2001). Working memory capacity and strategy use. Memory \& Cognition, 29, 10-17. http://dx.doi.org/10.3758/BF03195736

Maleha, N. (2003). Memory (short- long term) and its relationship with the ability to solve problems among tenth graders. Master Thesis, Gaza: Islamic University.

Swanson, H. (2011). Working memory, attention, and mathematical problem solving: A longitudinal study of elementary school children. Journal Educational Psychology, 103, 821-837. http://dx.doi.org/10.1037/a0025114

Turner, M. L., \& Engle, R. W. (1989). Is working memory capacity task dependent? Journal of Memory and Language, 28, 127-154. http://dx.doi.org/10.1016/0749-596X(89)90040-5

Zheng, X. H., Swanson, H. L., \& Marcoulides, G. A. (2011). Working memory components as predictors of children's mathematical word problem solving. Journal of Experimental Child Psychology, 110, 481-498. http://dx.doi.org/10.1016/j.jecp.2011.06.001 